\title{
Skinning a cat
}

\author{
Abe DeAnda, Jr, MD
}

\begin{abstract}
Almost 35 years ago, I sat in a comparative anatomy biology laboratory, preparing to dissect a specimen of Felis catus. In the otherwise staid and bland text of the prosector's guide, I still remember the opening statement: "Contrary to the popular adage, there is only one way to skin a cat." Our profession recognizes the presence of, and indeed the need for, multiple approaches to the care of a patient. Faced with an open aortic valve replacement, the surgeon must balance a triad of issues: (1) to maximize the effective orifice area (EOA) of the biologic prosthetic aortic valve (in part by not reducing the size of the annulus by the surgical technique of implantation), (2) to minimize the risk of a paravalvular leak, and (3) to optimize the ease of implantation.
\end{abstract}

In this issue of the Journal of Thoracic and Cardiovascular Surgery, Ugur and colleagues ${ }^{1}$ remind us that the old adage still holds true. A previous study by Tabata and associates $^{2}$ had suggested that a pledgeted everting mattress technique impeded the EOA of the bioprosthesis by the encroachment of annular tissue into the valve orifice. Tabata and associates $^{2}$ also noted that this technique could also result in a reduction of annular size, perhaps by a pursestring effect. They proposed that a simple interrupted (and therefore also nonpledgeted) technique would obviate these concerns. Kim and $\mathrm{Choi}^{3}$ agreed with Tabata and associates' assessment ${ }^{2}$ and added their own advocacy for a continuous suture technique, noting that the simple interrupted technique required more sutures to decrease the risk of paravalvular leak.

Ugur and colleagues ${ }^{1}$ have performed a post hoc analysis of data obtained from Food and Drug Administration (FDA) trial data evaluating the Trifecta (St Jude Medical Inc, St Paul, Minn) aortic valve. The FDA trial study had enrolled 1022 patients in 31 centers worldwide. ${ }^{4}$ The FDA did not mandate how the valve should be implanted. Most of the valves were $23 \mathrm{~mm}$ or larger; however, 399 of the valves were either $19 \mathrm{~mm}$ or $21 \mathrm{~mm}$. Of the 1014 valves eventually studied in the original FDA trial, 811 were implanted with a noneverting pledgeted technique. Other techniques used included continuous sutures

From the Department of Cardiothoracic Surgery, NYU Langone Medical Center, New York, NY.

Disclosures: Author has nothing to disclose with regard to commercial support.

Received for publication Aug 18, 2014; accepted for publication Aug 18, 2014.

Address for reprints: Abe DeAnda, Jr, MD, Department of Cardiothoracic Surgery,

NYU Langone Medical Center, 530 First Ave, Suite 9V, New York, NY 10016

(E-mail: abe.deanda@nyumc.org).

J Thorac Cardiovasc Surg 2014;148:1352-3

$0022-5223 / \$ 36.00$

Copyright (c) 2014 by The American Association for Thoracic Surgery

http://dx.doi.org/10.1016/j.jtcvs.2014.08.032 $(\mathrm{n}=57)$, everting pledgeted sutures $(\mathrm{n}=56)$, simple sutures $(\mathrm{n}=56)$, and nonpledgeted mattress sutures $(\mathrm{n}=$ 34). Ugur and colleagues ${ }^{1}$ focused on the subset of patients who had either a $19-\mathrm{mm}$ or a $21-\mathrm{mm}$ valve implanted and compared their outcomes according to implantation technique as noneverting pledgeted sutures (group 1) versus all other suture techniques (group 2). By assessing transvalvular gradients and EOA as well as indexed EOA, this study demonstrates that the noneverting pledgeted technique does not negatively affect the patient in terms of patient-prosthetic mismatch relative to the simple technique. In fact, whereas there was no difference in either the mean or peak gradient for either size valve, there did appear to be a favorable EOA and indexed EOA, at least for the $19-\mathrm{mm}$ valve, suggesting that technique does affect hemodynamic performance for the even smaller annulus. Because the range of indexed EOA was greater than 0.65 and less than or equal to 0.85 , the long-term clinical significance is unclear.

There are issues that one might have with the study, including the clustering of 3 techniques (group 2) for comparison, as well as the surprising discordance between transvalvular gradients and EOA. Assuming the overall results reflect the thesis of Ugur and colleagues ${ }^{1}$ that technique does not appear to matter, however, can we extrapolate to include other approaches? For example, LaPar and coworkers ${ }^{5}$ noted that a nonpledgeted technique provided equivalent results to those of pledgeted techniques, but with shorter crossclamp and cardiopulmonary bypass times. Some of the strongest evidence in favor of pledgets came from the Artificial Valve Endocarditis Reduction Trial (AVERT), although these results might be called into question given that the trial involved the Silzone valve (St Jude Medical) and that the trial was halted for valve-related issues. $^{6}$

Returning to my original thought, maybe there is only one way to skin a cat. Not as it relates to technique or valve choice, but rather to the individual surgeon's approach. Each surgeon should choose a technique and a valve that feels most comfortable and that will provide their patient with a safe, reproducible, and durable result. That is the universal goal. How you get there is your choice.

\footnotetext{
References

1. Ugur M, Byrne JG, Bavaria JE, Cheung A, Petracek M, Groh MA, et al. Suture technique does not affect hemodynamic performance of the small supra-annular Trifecta bioprosthesis. J Thorac Cardiovasc Surg. 2014;148: 1347-51.

2. Tabata M, Shibayama K, Watanabe H, Sato Y, Fukui T, Takanashi S. Simple interrupted suturing increases valve performance after aortic valve replacement
} 
with a small supra-annular bioprosthesis. J Thorac Cardiovasc Surg. 2014;147: 321-5.

3. Kim JH, Choi JB. Simple interrupted suturing for aortic valve replacement in a small aortic annulus. J Thorac Cardiovasc Surg. 2014;147: 2000-1.

4. Bavaria JE, Desai ND, Cheung A, Petracek MR, Groh MA, Borger MA, et al. The St Jude Medical Trifecta aortic pericardial valve: results from a global, multicenter, prospective clinical study. J Thorac Cardiovasc Surg. 2014;147: 590-7.
5. LaPar DJ, Ailawadi G, Bhamidipati CM, Singh M, Dare D, Kern JA, et al. Use of a nonpledgeted suture technique is safe and efficient for aortic valve replacement. J Thorac Cardiovasc Surg. 2011;141:388-93.

6. Englberger L, Schaff HV, Jamieson WR, Kennard ED, Im KA, Holubkov R, et al; AVERT Investigators. Importance of implant technique on risk of major paravalvular leak (PVL) after St. Jude mechanical heart valve replacement a report from the Artificial Valve Endocarditis Reduction Trial (AVERT). Eur J Cardiothorac Surg. 2005;28:838-43. 